\title{
ETHICAL EVALUATION OF COMPULSORY MEASLES IMMUNISATION AS A BENCHMARK FOR GOOD HEALTH MANAGEMENT IN THE EUROPEAN UNION
}

\author{
Peter Schröder-Bäck ${ }^{1}$, Helmut Brand ${ }^{1}$, Ixhel Escamilla ${ }^{7}$, John K. Davies ${ }^{2}$, Caroline Hall², Kieran Hickey ${ }^{3}$, \\ Eleni Jelastopulu ${ }^{4}$, Reli Mechtler ${ }^{5}$, Jaroslav Volf ${ }^{6}$ \\ ${ }^{1}$ Department of International Health, Faculty of Health, Medicine and Life Sciences, Maastricht University, The Netherlands \\ ${ }^{2}$ International Health Development Research Centre, Faculty of Health and Social Science, University of Brighton, UK \\ ${ }^{3}$ Health Service Executive, Dublin, Ireland \\ ${ }^{4}$ Laboratory of Public Health, University of Patras, Greece \\ ${ }^{5}$ Department of Health System Research, University of Linz, Austria \\ ${ }^{6}$ Permanent Mission of Czech Republic, Geneva \\ ${ }^{7}$ Department of Epidemiology and International Public Health, School of Public Health Bielefeld University, Germany
}

\begin{abstract}
SUMMARY
The results of the study Benchmarking Regional Health Management II suggest that compulsory measles immunisation is a good practice in public health management. Yet, the potential achievement of the desired health outcome alone is not a sufficient reason to make the immunisation obligatory. Rather, compulsory measles immunisation is a morally challenging measure. In this article, compulsory measles immunisation is critically evaluated from a public health ethics point of view. For this evaluation, a set of ethical criteria is proposed: respect for autonomy, health maximisation, efficiency, proportionality and social justice. The authors suggest it should not be taken for granted that compulsory measles immunisation should be championed, rather, health policy makers in the European Union should try to raise immunisation rates with non-compulsory means.
\end{abstract}

Key words: measles, immunisation, compulsion, ethics, European Union

Address for correspondence: P. Schröder-Bäck, Maastricht University, Faculty of Health, Medicine and Life Sciences, Department of International Health, Division European Public Health \& Ethics, P.O. Box 616, 6200 MD Maastricht, The Netherlands. E-mail: Peter.Schroder@INTHEALTH. unimaas.nl

\section{INTRODUCTION}

The Benchmarking Regional Health Management II study (Ben II, EU project 2003106) compared the public health management systems of 19 European regions with regard to their structures, processes, policies and health outcomes. The analysis was conducted along three tracers: measles immunisation, breast cancer screening and care and diabetes (type II) care. Among the examples of good practice for measles immunisation, the Ben II study identified two regions that fulfil the criteria for good practice. These regions are Moravia-Silesia (Czech Republic) and Szabolcs-Szatmár-Bereg (Hungary). They achieved very high rates of uptake for the first and second doses of measles immunisation, in 2005 close to or above $95 \%$. The study found that these regions have compulsory measles immunisation policies. Despite this finding, compulsory measles immunisation is neither necessary [e.g. Madeira (Portugal) reaches also 95\% for the second measles immunisation dose without compulsory measles immunisation], nor necessarily sufficient for high immunisation rates (Western Greece also has compulsory measles immunisation but immunisation rates are not that high) (1). The authors of the BEN II study found compulsory measles immunisation to be a public health measure that requires ethical discussions.
Thus, in this paper the authors examine if, or under what conditions, a compulsory measles immunisation would be ethically justified. Firstly an ethical framework to present plausible criteria for discussion is presented. In other words, moral benchmarks for ethically justified good conduct of public health measures are offered. The paper goes on to show how these criteria may be used to support a robust argument in this regard.

\section{AN ETHICAL FRAMEWORK}

Principles are useful tools for medical and public health ethics (2). To find guidance for ethical evaluation, one can use a concise set of broad ethical principles. A framework for public health ethics has to be different from that one of medical ethics due to the different perspectives and duties public health and medicine have. Generally, in medical ethics one uses the principles: respect for autonomy, beneficence, non-maleficence and justice (3); such principles focus on bringing good to patients or research subjects without harming them or making them means to someone else's ends.

Public health ethical principles can consist of the following generalised norms that reflect the public health enterprise to main- 
tain and promote population health - whilst still acknowledging "side constraints" (4) that remind practitioners that populations consist of valuable individuals. These principles are: health maximisation, respect for human dignity, social justice, efficiency and proportionality (Table 1) (5). These principles can be considered an "ethical toolbox" for public health practitioners and scientists and benchmarks for ethically good and right public health research and practice. It is the role of public health practitioners and researchers to balance these principles in their daily work and/or specify them to more concrete moral rules and judgments within particular contexts. This ethical framework shall be discussed and argued for in this paper, following initial explanation of the principles themselves.

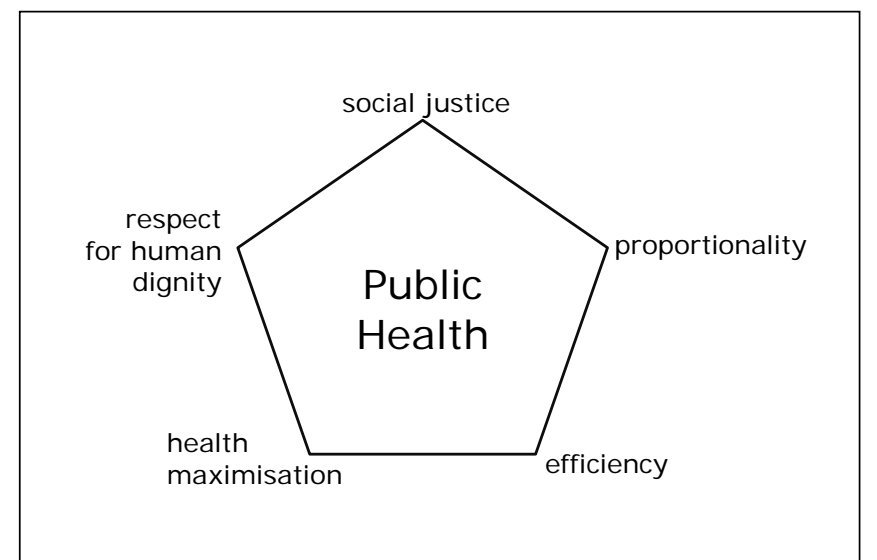

Fig. 1. The matrix of a principled public health ethics framework.

Health Maximisation. This principle is for public health what "beneficence" is for medical practice. Both enterprises - public health and medicine - try to generate good health. Whereas "beneficence" is traditionally the principle of personal ethics to describe a moral duty of the physician to his/her patient; "health maximisation" is a variant of the principle "social utility" for social ethics. The net-benefit of "health maximisation" is to be sought in the whole of the population that is under consideration. Some people in public health believe that "social utility" is at the heart of public health and many public health practitioners came into public health to facilitate maximum health gain within the target population (6). Others, such as Miettinen (7), even insist that there cannot be any other moral norm than social utility to guide the practice of public health. A position which can be challenged by introducing further principles into the ethical toolbox.

Respect for Human Dignity. If only "health maximisation" was focused as a moral norm to abide by public health practice and research, this might have devastating consequences. It would then be allowed to use individuals (or whole groups) for other than their own ends and even sacrifice them if only this provided a greater net-benefit, i.e. maximised health. Although in extreme cases it might be ethically permissible to restrict individual liberty, for example when a person with a contagious and deadly disease, who resists going voluntarily into isolation is forced to do so, or is not allowed to use an airplane - "respect for human dignity" reminds us of our duty not to sacrifice or exploit individuals and to respect their free wills, their self-determination (8).

Social Justice. "Social Justice" is another side constraint to "health maximisation". It does not only matter to enhance the net-benefit; it also matters how the benefits and burdens are distributed. At the core of public health research there are questions of health inequalities. Until now, it is not $a$ priori clear what inequalities are justified and which are morally unacceptable (or “inequities" are) (9). Social justice is the norm that tries to keep public health from discrimination, stigmatisation and exclusion. It promotes fair treatment for those who have less chances for health and less chances to lead a full and flourishing life (10) - regardless of whether supporting this population means that the overall net-benefit rises (or not).

Efficiency. When goods are distributed - raising the netbenefit and bringing health to all, or supporting the most disadvantaged - "efficiency" becomes an essential principle that needs to be included in the concise set of principles for public health ethics. Although it seems only to support social utility or social justice through guidance to spend resources responsibly, it has to be a principle at the forefront of public health practice - particularly in prevention.

The resources of public health systems are limited. Thus, the efficient use and distribution of scarce resources is a moral duty, which results in greater benefit to more people, including disadvantaged individuals and groups. The principle "efficiency" is thus demanded by the public health discipline, for example through the use of evidence-based public health measures and the implementation of cost-benefit-analysis. It should be included in the concise set of ethical principles in order to permanently reassure public health practitioners and researchers that to be efficient and not wasteful is also a moral duty.

Proportionality. The fifth ethical principle demands that when weighing and balancing individual freedoms against the social good, this should be achieved proportionally. In the words of Childress et al. it is "essential to show that the probable public health benefits outweigh the infringed general moral considerations. All of the positive features and benefits must be balanced against the negative features and effects" (11).

In addition to this general ethical framework, we want to introduce in this context ethical criteria for immunisation programmes as presented by Verweij and Dawson (Table 1) (12). They propose seven criteria that reflect the five principles named above ${ }^{1}$. Their criterion 5 is identical with the principle social justice. Other criteria are a melange of ethical principles. They are specifications of our ethical principles; this means, they consider different principles in one criterion. The criterion 6 , for example, reflects the right to self-determination - as reflected in the principle of respect for human dignity - and health maximisation. Criterion 1 corresponds with health maximisation, as do criteria 2 and 3 . They aim at maximising health and specify this more concretely for the purpose of health im-

\footnotetext{
${ }^{1}$ They actually call their criteria principles. Yet, not to confuse their criteria with the used ethical principles that are rather generalised ethical norms in accordance with the methodology and nomenclature of applied ethics, we continue to call them criteria.
} 
Table 1. Ethical criteria for the implementation of immunisation programmes (12)

1. Collective vaccination programmes should target serious diseases that are a public health problem.

2. Each vaccine, and the programme, as a whole must be effective and safe.

3. The burdens and inconveniences for participants should be as small as possible.

4. The programme's burden/benefit ratio should be favourable in comparison with alternative vaccination schemes or preventative options.

5. Collective vaccination programmes should involve a just distribution of benefits and burdens.

6. Participation would, generally, be voluntary unless compulsory vaccination is essential to prevent a concrete and serious harm.

7. Public Trust in the vaccination programme should be honoured and protected.

munisation programmes. Criterion 5 relates to justice. Criterion 4 considers aspects of proportionality and efficiency. Criterion 7 asks for public trust, which is demanded and morally justified by respect for human dignity and can lead to a maximisation of health by a complying population.

In general, these criteria appear very plausible. Taking them into context of the five principles of the general public health ethics framework, these criteria indeed even support the five principles as their very specifications.

\section{ETHICAL DISCUSSION OF COMPULSORY IMMU- NISATION}

After having presented the principle-based general ethical framework and the more specific ethical criteria for immunisation programmes that are compatible with the five principles, the question if compulsory collective measles immunisation programmes can find ethically justification will now be discussed.

\section{The Perspective from Efficiency, Health Maximisa- tion, Social Justice and Proportionality}

A moral aim of public health is to do good and to maintain and improve health for as many people as possible. The focus on measles is a legitimate topic, since measles are a highly contagious disease and within a global perspective, a principal cause of death or disability among children (13). Even though effective, convenient and safe vaccination exists, measles have not been eradicated in Europe. To offer measles immunisation as a public health measure meets the principle of health maximisation and the criteria 1-3. Moreover - from an economic point of view - measles immunisation is highly efficient in terms of its cost-benefit ratio (14) - thus criterion 4 is met as well. And in accordance with the safety of measles immunisation and the maximisation of health that can be achieved by reaching herd protection, criterion 4 is also met and with it the proportionality principle.

Since uptake rates of measles immunisation remain inadequate the situation is such that many European regions are far from achieving herd protection (1). Is it therefore a good reason to make immunisation obligatory where herd immunity is lacking? This might still be considered to be proportional and just as everyone thus has equal chances of receiving vaccination and not suffering from the disease. This would include the weakest subpopulation, namely those who are for immunological reasons not eligible for immunisation and thus have to rely on herd immunity to be protected against measles. Furthermore, it could even be said that once herd immunity would be guaranteed, there should be still compulsory immunisation so that immunisation risks are just and fairly distributed and in particular "free-riders" (those who do not get immunisation for their children but rely on others to immunise their children) can be prevented (criterion 5).

In either way, to distribute the benefits and burdens of immunisation justly (criterion 5), vaccination must be offered to everyone. If information campaigns for measles immunisation are to take place, justice also demands not to stigmatise certain social groups who do have a lack of immunisation uptake. This may be due to reasons related to their social status or due to their cultural and/or religious beliefs. The justice perspective has to safeguard the moral conviction that social status alone might not be grounds to have less protection against measles or suffer from any stigmatisation or discrimination in this context. To follow these aspects is also important to keep public trust (as demanded in criterion 7).

\section{The Perspective from Human Dignity}

Compulsory immunisation against infectious and communicable diseases is aimed at achieving herd immunity instead of merely protecting immunised individuals. In this case, herd immunity would be a public good. The more serious the avoidable disease and the greater its impact, the higher is the value of the public good and its benefit for the population. Individuals though might act as "free-riders". In this case they would avoid immunisation and thus not contribute to this public good but would profit from high immunisation rates that are the results of others getting immunised. Such a "free-rider culture" could of course hardly be justified with the respect of human dignity as understood under Immanuel Kant's classic conception of autonomy (15) - the bedrock of human dignity. Kant's reason is that the maxim of this individual search for advantage ("I will not have myself immunised but want to profit from the immunisation of other people!”) cannot be universalised. It fails the test of the Categorical Imperative. The Categorical Imperative states that maxims of actions only 
are consistent with human dignity if they are universalisable, i.e. everyone can act on them. In economic terms, this egoistic "free rider" view of achieving public good would lead to market failure (14). If everyone acted on this maxim, no herd immunity would be achieved.

Following the Kantian approach, parents rather ought to argue: "I must accept the low risk of immunisation complications to protect my child against the much more probable measles disease which might involve fatal risks. I cannot demand from others what I myself am not prepared to give. Moreover, through immunisation and building up herd immunity I will also protect those children who for immunological reasons must not be immunised."

Thus, on the one hand, the principle respect for human dignity interpreted in this Kantian manner would demand from every parent to vaccinate their child against measles and not to become free-riders. Yet, public health is not about inner states of parents but takes a population perspective. And the question would be: May state authorities force parents to vaccinate their children? Even if vaccination is demanded by respecting human dignity from certain perspectives, on the other hand, it also asks the state not to be intrusive and disrespect own decisions. Respecting for human dignity demands that force is to be avoided, as long as it is proportional not to force (criterion 6). Force might be proportional if the harm that would follow is greater; then the principle of health maximisation would trump the principle of respecting human dignity. Yet, in most EU populations, the vaccination rate is already quite high. Thus, there would not be so good reasons for compulsory measles vaccination compared to obligatory immunisation for example against small pox in a worldwide small pox outbreak. The value of the non-interference with selfdetermination (of parents on behalf of their children) is given a greater weight here.

\section{CONCLUSIONS AND OUTLOOK}

Force as interference with one's self-determination is particularly recognisable in the case of compulsory measles immunisation; above all because in contrast, for example to hip screenings for infants, injecting a substance constitutes an intrusion into the human body with great symbolic meaning. Compulsory immunisation measures against the acute massive distribution of a pandemic might be more justifiable due to a larger number of human lives which could potentially be saved (giving the principle of health maximisation most weight). However, the overall health benefit of obligatory measles immunisation in the European Union is of relatively minor importance. This is because a specific immunisation level has already been achieved, although not yet that of the desired herd immunity. Also, the principle of respect for human dignity and thus self-determination weighs higher than the moral value of stopping free riders, even though the justice perspective would recommend distribution of benefits and burdens fairly.

Nevertheless, the reasons for compulsory measles immunisation in the European Union do not seem to outweigh the violation of self-determination, particularly not when it becomes clear that there are still other methods to achieve the desired herd immunity. It could be argued therefore that through better information and health promotion policy, by building up acceptance and confidence into immunisation based on transparent reasons, which are convincing because of their scientific quality, and by creating accurate incentives for immunisation it should be possible to achieve herd immunity (14). We have to give priority in the European Union to these activities before considering the further implementation of compulsory measles immunisation in EU member states.

\section{REFERENCES}

1. Benchmarking Regional Health Management II (Ben RHM II). Final Report. Bielefeld: Lögd; 2007.

2. Coughlin SS, Soskolne CL, Goodman KW, editors. Case studies in public health ethics. Washington, DC: American Public Health Association; 1997.

3. Beauchamp TL, Childress JF. Principles of biomedical ethics. 6th ed. New York: Oxford University Press; 2008.

4. Nozick R. Anarchy, state and utopia. New York: Basic Books; 1974.

5. Schröder-Bäck P. Principles for public health ethics - a transcultural approach. Eubios J Asian Int Bioeth. 2007 Jul;17(4):104-8.

6. Mackenbach J. Kos, Dresden, Utopia ... A Journey through idealism past and present in public health. Eur J Epidemiol. 2005;20(10):817-26.

7. Miettinen OS. Idealism and ethics of public-health practitioners. Eur J Epidemiol. 2005;20(10):805-7.

8. Geier M, Schröder P. The concept of human dignity in biomedical law. In: Sándor J, den Exter AP, editors. Frontiers of the European health care law: a multidisciplinary approach. Rotterdam: Erasmus University Press; 2002. p. 146-82.

9. Powers M, Faden RR. Social justice: the moral foundations of public health and health policy. Oxford: Oxford University Press; 2006.

10. Schröder P. Justification of gene diagnostic: an study on the challenges of postnatal prediction. Münster: Lit; 2004. (In German.)

11. Childress JF, Faden RR, Gaare RD, Gostin LO, Kahn J, Bonnie RJ, et al. Public health ethics: mapping the terrain. J Law Med Ethics. 2002;30(2):170-8.

12. Verweij M, Dawson A. Ethical principles for collective immunisation programmes. Vaccine. 2004 Aug 13;22(23-24):3122-6.

13. World Health Organization [homepage on the Internet]. Measles. Fact sheet $N^{\circ} 286$. Revised December 2008 [cited 2009 Sep 14]. Available from: http://www.who.int/mediacentre/factsheets/fs286/en/index.html.

14. Marckmann G. Vaccination programs between individual autonomy and common welfare. Bundesgesundheitsblatt Gesundheitsforschung Gesundheitsschutz. 2008 Feb;51(2):175-83. (In German.)

15. Kant I. Fundamentals of the metaphysics of morals. In: Weischedel W, editor. Works in ten volumes. Volume 6. Darmstadt: Wissenschaftliche Buchgesellschaft; 1964. (In German.) 